\title{
Pachydermoperiostosis: a rare mimicker of acromegaly
}

\author{
Noor Rafhati Adyani Abdullah', Wong Lok Chin Jason² and Azraai Bahari Nasruddin' \\ ${ }^{1}$ Endocrinology Unit, Department of Medicine, Putrajaya Hospital, Putrajaya, Malaysia and 2Department \\ of Medicine, National University of Malaysia Medical Centre, Kuala Lumpur, Malaysia
}

Correspondence should be addressed to N R A Abdullah Email

adyania@yahoo.com

\section{Summary}

Pachydermoperiostosis is a very rare osteoarthrodermopathic disorder whose clinical and radiographic presentations may mimic those of acromegaly. In the evaluation of patients with acromegaloid appearances, pachydermoperiostosis should be considered as a differential diagnosis. In this article, we report a 17-year-old boy who presented with 2-year history of acral enlargement and facial appearance changes associated with joint pain and excessive sweating. He had been investigated extensively for acromegaly, and the final diagnosis was pachydermoperiostosis.

\section{Learning points}

- There is a broad range of differential diagnosis for acromegaloid features such as acromegaly, pseudoacromegaly with severe insulin resistance, Marfan's syndrome, McCune-Albright and a rare condition called pachydermoperiostosis.

- Once a patient is suspected to have acromegaly, the first step is biochemical testing to confirm the clinical diagnosis, followed by radiologic testing to determine the cause of the excess growth hormone (GH) secretion. The cause is a somatotroph adenoma of the pituitary in over 95 percent of cases.

- The first step is measurement of a serum insulin-like growth factor 1 (IGF1). A normal serum IGF1 concentration is strong evidence that the patient does not have acromegaly.

- If the serum IGF1 concentration is high (or equivocal), serum GH should be measured after oral glucose administration. Inadequate suppression of GH after a glucose load confirms the diagnosis of acromegaly.

- Once the presence of excess GH secretion is confirmed, the next step is pituitary magnetic resonance imaging (MRI).

- Atypical presentation warrants revision of the diagnosis. This patient presented with clubbing with no gigantism, which is expected in adolescent acromegalics as the growth spurt and epiphyseal plate closure have not taken place yet.

\section{Background}

Pachydermoperiostosis (PDP), otherwise known as primary hypertrophic osteoarthropathy, is a rare hereditary disorder. In complete form, it is characterized by pachyderma (thickened facial skin), skeletal changes (periostosis), excessive sweating (hyperhydrosis) and acropachia (digital clubbing). Making a diagnosis followed by a proper care plan can be extremely challenging even for the most experienced clinicians due to the rarity of this disease. The clinical features, signs and symptoms have stark similarities with acromegaly and can cause diagnostic confusion. We report a young male with gradual coarsening of his facial features, bilateral hand and feet enlargement associated with pachyderma, excessive sweating and arthralgia for nearly two years. He had been extensively investigated for acromegaly, and the final diagnosis was pachydermoperiostosis. 


\section{Case presentation}

A 17-year-old male was referred to the endocrinology clinic with complaints of bilateral enlargement of his hand and feet for the past 2 years. His shoe size had increased drastically (from a size 7 to 13) over a period of 1 year. His background medical problems included G6PD deficiency and mild peptic ulcer disease for which he underwent endoscopy in 2015, treated with a short course of proton pump inhibitor and asymptomatic since then. Further questioning revealed that his facial features had coarsened over the preceding year. He developed large nose, thick lips, prominent chin, large tongue and difficulty to chew food. He also developed excessive sweating and greasy skin. Comparison made with his photographs revealed prominent differences to his previous appearance. The facial and acral enlargement led to significant social embarrassment and difficulty finding appropriate shoes. He also complained of intermittent occipital headache, which was not associated with any visual disturbances. He had bilateral knee and ankle pain associated with bilateral knee swelling. The knee pain greatly limited his mobility, and he was unable to walk long distance or participate in sports. The fingers and wrists were enlarged without any associated numbness. He had no heart failure symptoms or reduced effort tolerance. However, he snored during sleep and suffered from daytime somnolence, early morning lethargy and irritability. He was the second of four siblings with normal antenatal and neonatal history. He had normal milestones with average academic performance in school. His height was average among his schoolmates. He reached pubertal spurt at the age of 14 years with normal libido and normal development of secondary sexual characteristics. He did not have proximal myopathy and did not require to shave due to absence of facial hair. All family members were normal phenotypically except for a paternal uncle with large fingers and clubbing that has never been investigated.

On clinical examination, BMI was $19.5 \mathrm{~kg} / \mathrm{m}^{2}$ with weight of $57 \mathrm{~kg}$ and height of $171 \mathrm{~cm}$. His height was as expected based on midparental height calculation (father's height $175 \mathrm{~cm}$, mother's height $154.5 \mathrm{~cm}$ ). BP was 101/65, PR: 94, apex beat undisplaced, normal heart sounds with no murmur, lungs clear, abdomen soft with no organomegaly. He had coarse facial features with prognathism, prominent nose, thick lips, macroglossia and deep furrowing of his forehead skin (cutis verticis gyrata) (Fig. 1, 2, and 3). His visual fields were intact. He had spade-like hands and feet with thick doughy skin (Figs. 4 and 5). His palms and soles were notably sweaty

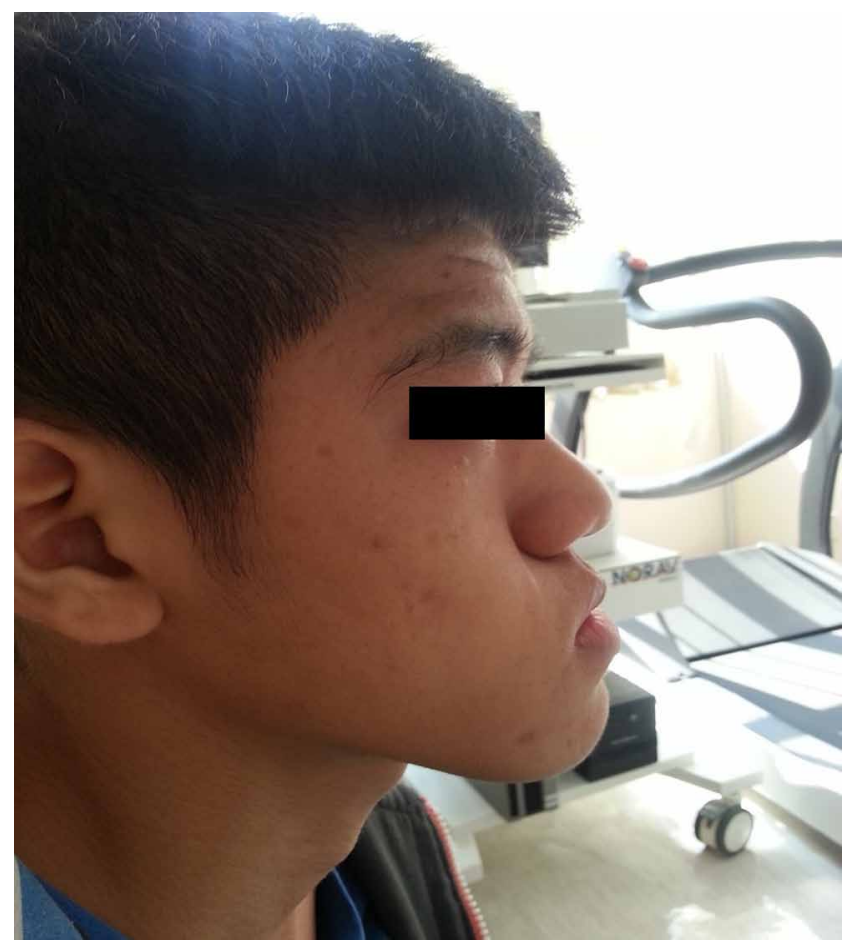

Figure 1

Acromegaloid facies with prominent nose and prognathism.

and moist. He did not have goitre, acanthosis nigricans or skin tags. He was also noted to have clubbing of his fingers and toes. He had no chest or axillary hair and Tanner

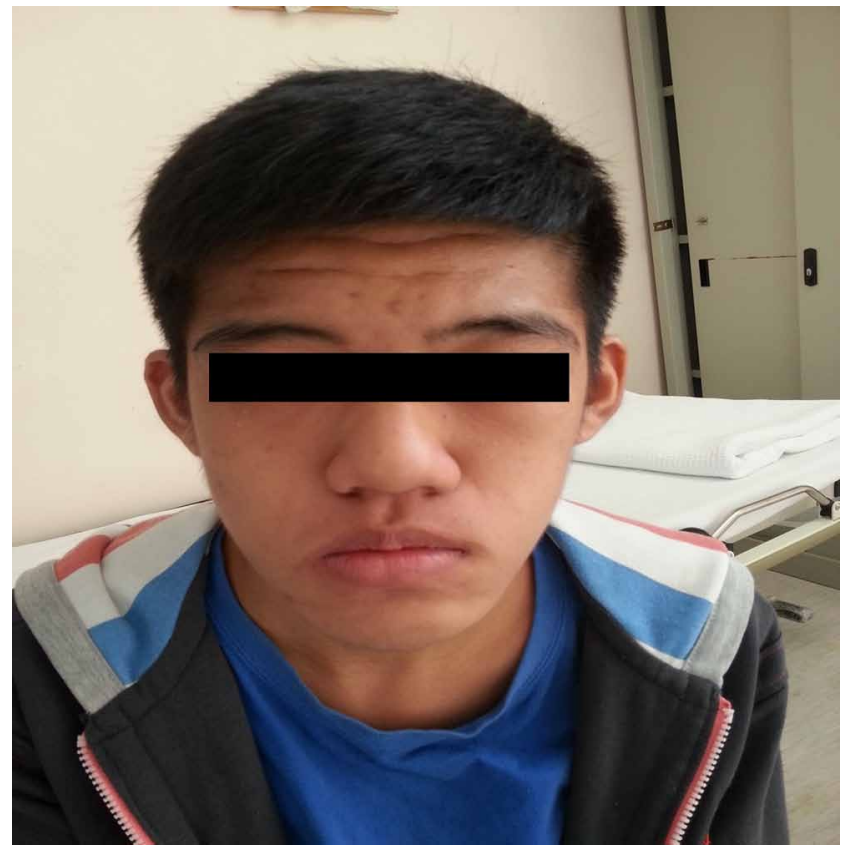

Figure 2

Acromegaloid facies with prominent nose, prognathism, thick lips and deep furrowing of his forehead skin (cutis verticis gyrate). 


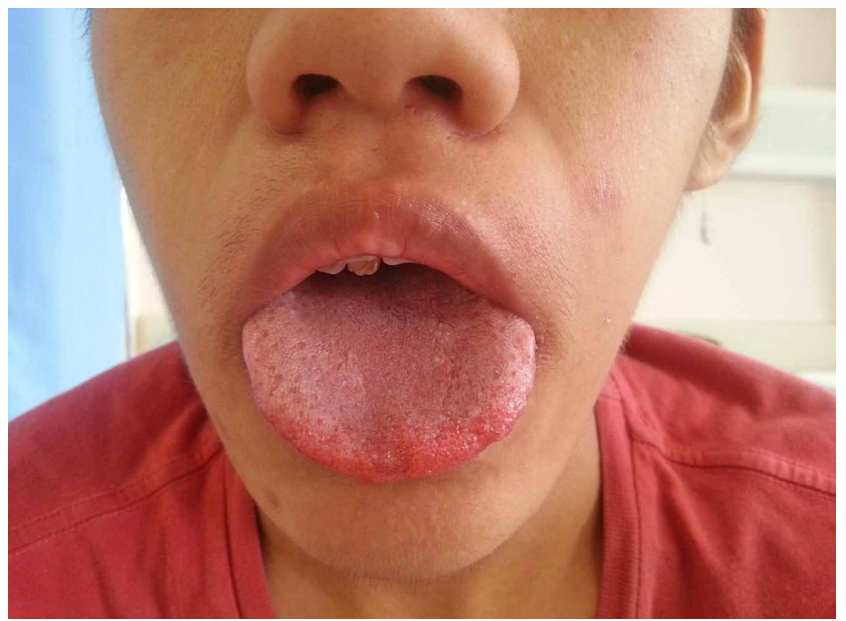

Figure 3

Macroglossia.

Stage was 3. He had no other abnormal skin lesions and the testicular volumes were $25 \mathrm{mls}$ bilaterally. Both knees were grossly swollen with effusions (Fig. 6).

\section{Investigation}

For 2 years, he had been visiting another tertiary hospital and had been worked up extensively for acromegaly. His blood investigations showed IGF1: $118 \mu \mathrm{g} / \mathrm{L}$ (146-415), fasting GH: $0.45 \mu \mathrm{g} / \mathrm{L}(0-3), \mathrm{TSH}: 2 \mathrm{mIU} / \mathrm{L}(0.35-4.94)$, fT4: $17.36 \mathrm{pmol} / \mathrm{L}$ (9-19), prolactin: $334 \mathrm{mIU} / \mathrm{L}$, morning cortisol: $212 \mathrm{nmol} / \mathrm{L}, \mathrm{HbA1c}$ : $.2 \%$, LH: $1.8 \mathrm{IU} / \mathrm{L}$ (1.7-8.6), FSH: $4.4 \mathrm{IU} / \mathrm{L}(1.5-12.4)$ and testosterone: $4.2 \mathrm{nmol} / \mathrm{L}$ (10-38.5). Short Synacthen test showed adequate cortisol response to ACTH with peak cortisol of $914 \mathrm{nmol} / \mathrm{L}$ at

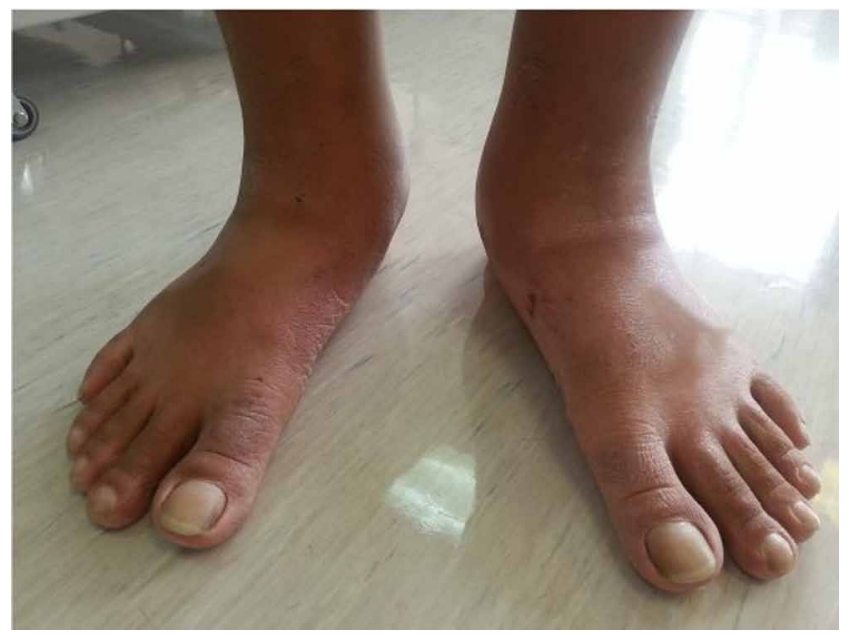

Figure 4

Spade-like feet with thick doughy soles and clubbing of toes

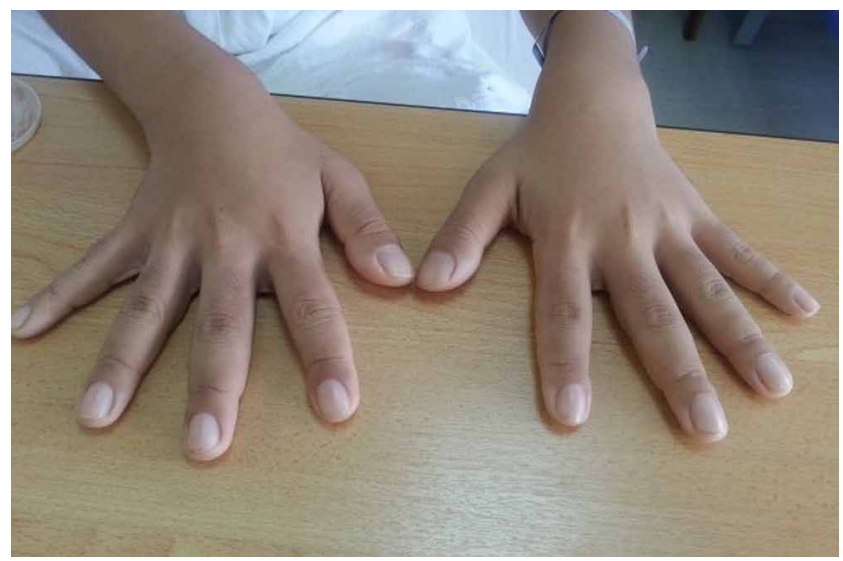

\section{Figure 5}

Spade-like hands with thick doughy palms and clubbing of fingers.

$60 \mathrm{~min}$. Oral glucose tolerance test (OGTT) with $75 \mathrm{~g}$ oral glucose revealed no evidence of diabetes or prediabetes and $\mathrm{GH}$ was well suppressed less than $1 \mu \mathrm{g} / \mathrm{L}$. Echo showed EF $54 \%$ with normal chambers and valves. The MRI pituitary was done twice and both showed normal pituitary gland with normal stalk and optic chiasm. The investigations were repeated in our centre with IGF1: $135.5 \mathrm{ng} / \mathrm{mL}$ (111509), ACTH: $5.2 \mathrm{pmol} / \mathrm{L}$, fasting GH: $0.4 \mathrm{mcg} / \mathrm{L}$ (0.07-5), morning cortisol: $316 \mathrm{nmol} / \mathrm{L}$, prolactin: $110 \mathrm{mIU} / \mathrm{L}, \mathrm{LH}$ : $2.9 \mathrm{IU} / \mathrm{L}(2-5.3)$, FSH: 6IU/L (1.8-5.1), TSH: $4.8 \mathrm{mIU} / \mathrm{L}$ (0.9-3.1), fT4: $19.1 \mathrm{pmol} / \mathrm{L}$ (7.8-13.2), testosterone: $19.7 \mathrm{nmol} / \mathrm{L}$ (9-29), corrected Ca: $2.3 \mathrm{mmol} / \mathrm{L}$, PO4: $1.46 \mathrm{mmol} / \mathrm{L}$ and FBS: $4.6 \mathrm{mmol} / \mathrm{L}$. The OGTT again demonstrated normal suppression of GH less than $1 \mu \mathrm{g} / \mathrm{L}$. ESR and CRP were normal. His radiographs revealed

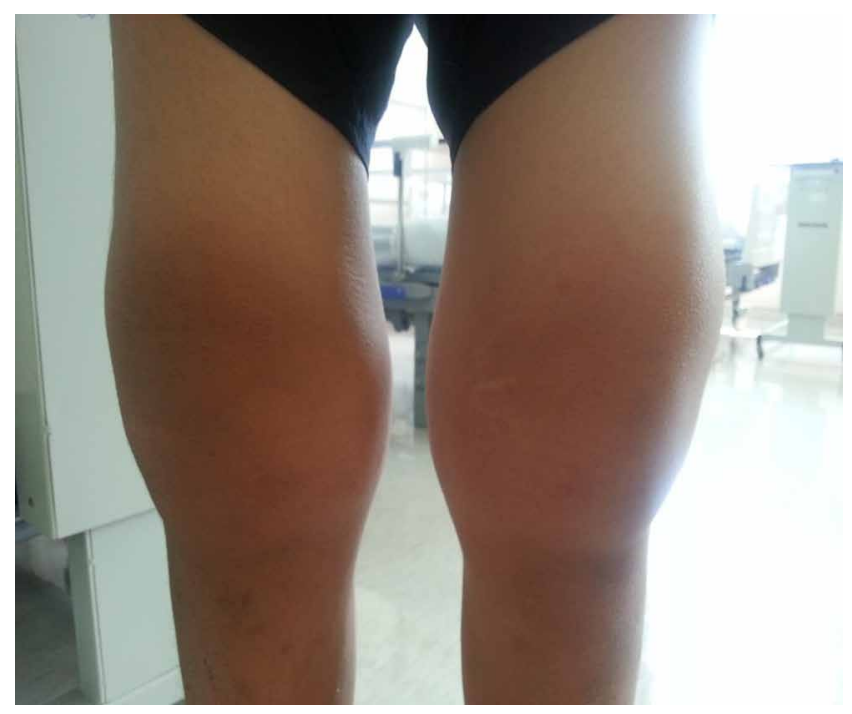

Figure 6

Gross bilateral knee effusions. 


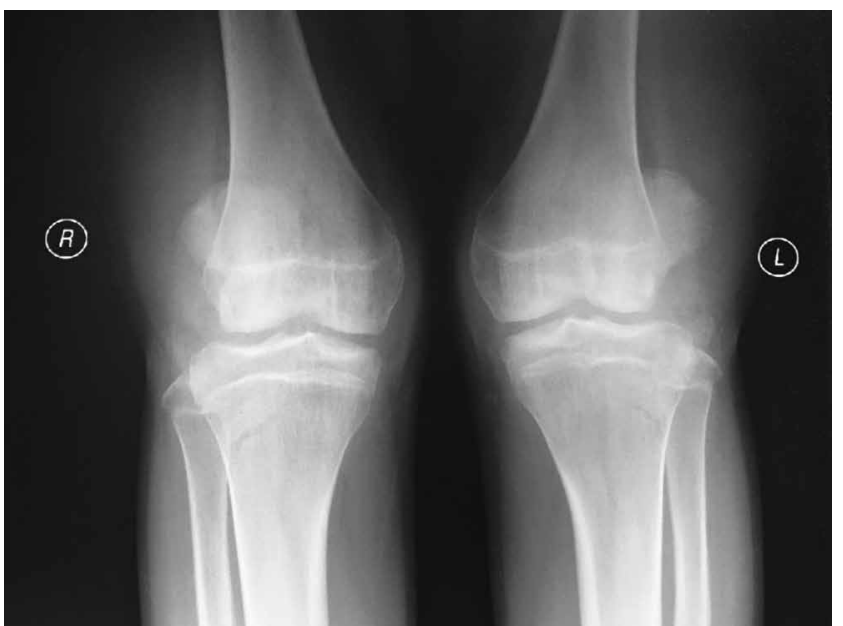

Figure 7

Radiograph of bilateral knee joints with periarticular soft tissue swelling and thickening.

prominent soft tissue thickening of both knees and hands and posterior cortical thickening with subperiosteal new bone formation of bilateral fibula (Figs. 7 and 8). The fat pad was thickened with no acro-osteolysis and ossification of the ligaments. Musculoskeletal ultrasound showed synovial proliferation with evidence of synovitis over the knees and ankles with massive synovial fluid collection of both the knees. Skin biopsy of his left leg showed focal hyperkeratosis and parakeratosis with the dermis showing increase in dermal collagen (Figs. 9 and 10). The dermal collagen appeared fragmented and some of the collagen fibres were thickened. Dermal oedema with variable amount of interstitial mucin content was

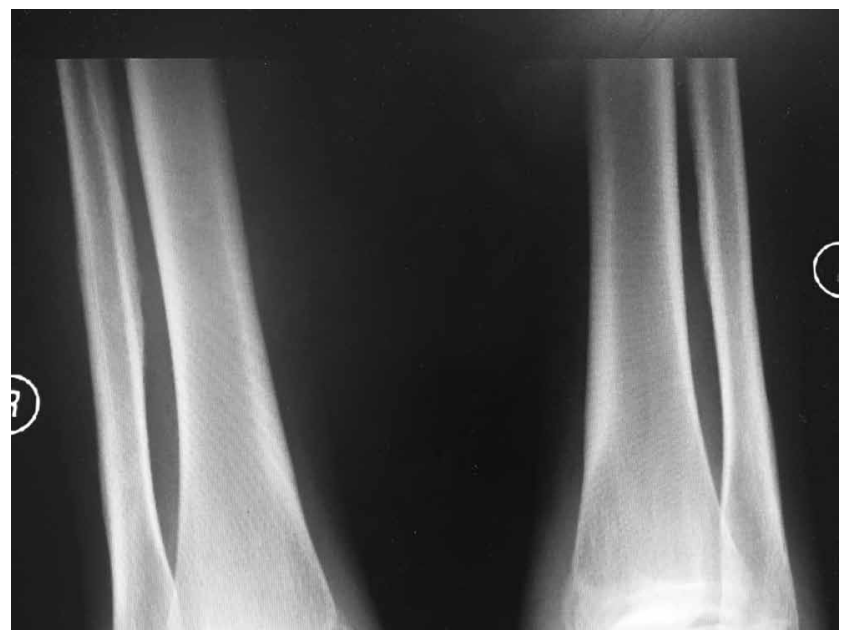

\section{Figure 8}

Radiograph of tibia/fibula which demonstrated posterior cortical thickening with subperiosteal new bone formation of bilateral fibula.

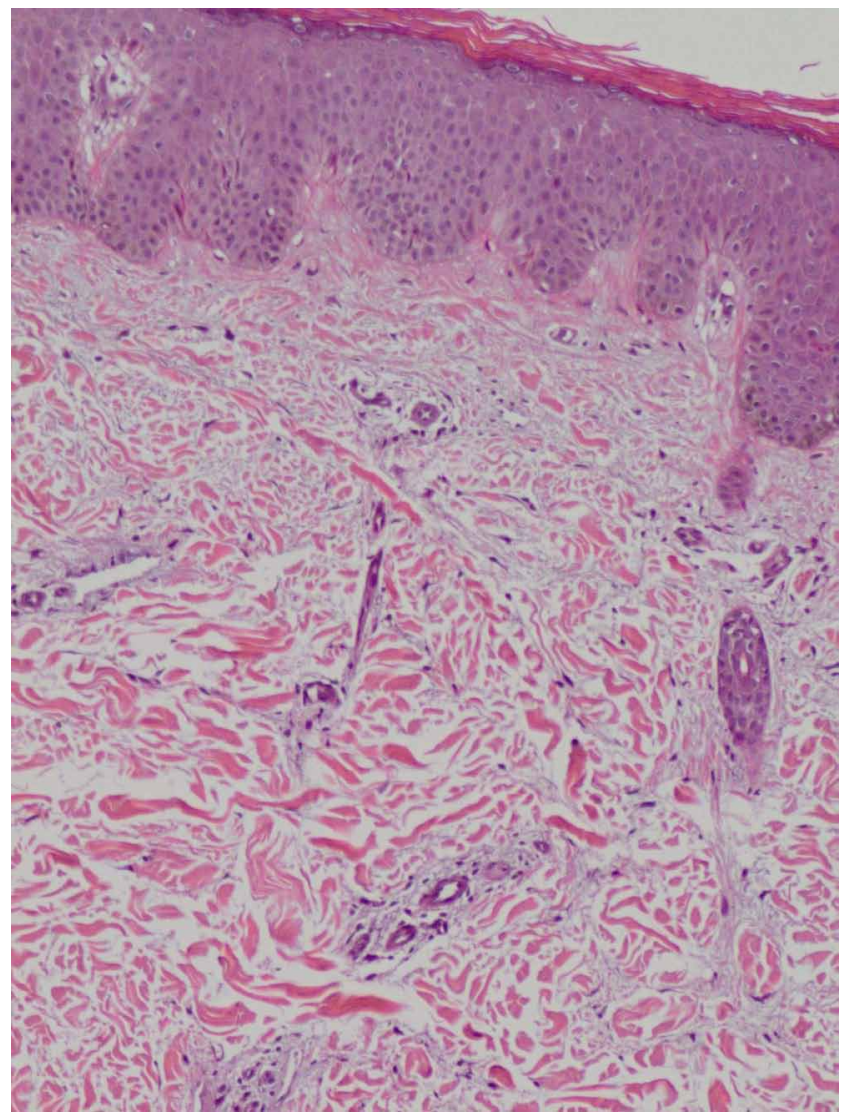

\section{Figure 9}

Histological imaging of skin biopsy.

noted within the spaces between the collagen fibres. Dermal mucinosis with increased collagen deposition (sclerodermoid change) was noted. The findings were supportive of pachydermoperiostosis. Based on the clinical, radiological and the histopathological features in the absence of $\mathrm{GH}$ hypersecretion, a diagnosis of pachydermoperiostosis was made.

\section{Treatment}

Subsequently, he was managed under the multidisciplinary care of endocrinologists, rheumatologists, dermatologists, psychiatrists and geneticists. His treatments consisted of non-steroidal anti-inflammatory drugs (NSAIDs) for pain relief, and he refused therapeutic knee joint aspiration.

\section{Outcome and follow-up}

He responded well to the NSAIDs and after 2 years of follow-up, the disease process ceased with no further acral enlargement and facial changes. The gross knee effusion persisted, but he was no longer debilitated by pain. 


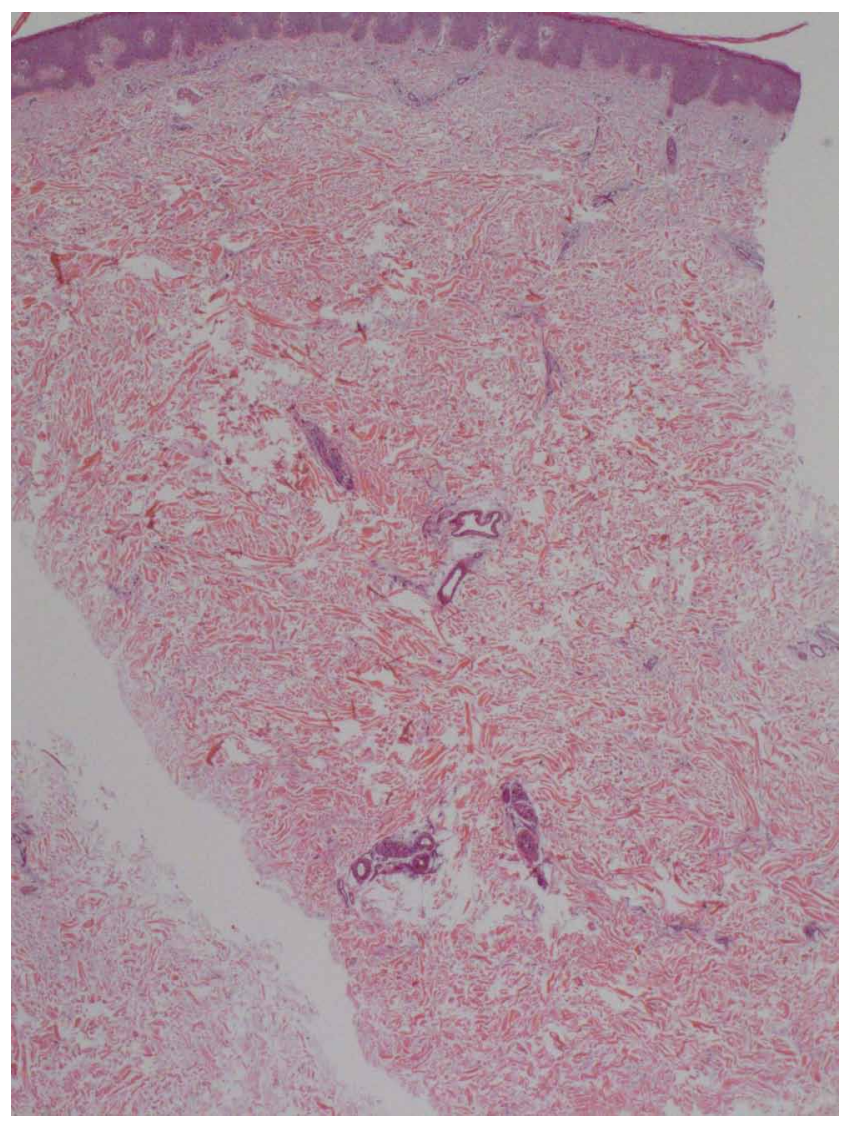

Figure 10

Histological imaging of skin biopsy.

\section{Discussion}

Pachydermoperiostosis is a rare hereditary disorder, which mainly appears as an autosomal dominant pattern with variable penetrance $(1,2)$. The precise incidence is unknown. It was first described by Friedreich in 1868 when he wrote about two brothers who had the disease (3). Adolescent males are predominantly affected with male-to-female ratio of approximately 7:1. Typically, men are affected more severely than women. It begins during childhood or adolescence and progresses gradually over the next 5-20 years before stabilizing. The development typically ceases after 10 years, but patients may be left with chronic debilitating complications, which include severe kyphosis, restricted motion, and neurologic manifestations. Life expectancy may be normal. The typical presentations include thickening and coarsening of skin and/or scalp (pachydermia), clubbing of digits, oedema in the lower legs, arthritis both with and without joint effusion and periostosis (swelling of periarticular tissue and subperiosteal new bone formation). It is associated with pain, polyarthritis, cutis verticis gyrata, seborrhoea and hyperhidrosis. It is the primary form of hypertrophic osteoarthropathy (HPOA), whereas the secondary HPOAs exist with underlying diseases such as malignancy (4). Diagnosis of pachydermoperiostosis is made clinically based on the combination of digital clubbing and periostosis of tubular bones. It can be classified as complete or incomplete depending on the extent of clinical presentation of symptoms and signs.

This patient, by definition seemed to have the complete form of primary pachydermoperiostosis since pachydermia, clubbing and periostosis were observed. The pathogenesis of PDP is not yet clearly understood; however, the previous evidence suggest that vascular endothelial growth factor (VEGF) and platelet-derived growth factor (PDGF) could play a central role (5). VEGF is produced in malignancies and is induced under hypoxic circumstances. This could explain the cause of vascular hyperplasia, new bone formation and oedema, which are classic presentations of HPOA (5). However, more recent studies demonstrated prostaglandin mediated pathway as the key player in the pathogenesis of PDP. Homozygous mutations in the 15-hydroxyprostaglandin dehydrogenase (HPDG) result in an elevated prostaglandin E2 level and has been suggested as a pathogenesis of PDP $(6,7)$. Subsequently, mutations in the prostaglandin transporter gene, SLCO2A1, were identified via exome sequencing as the pathogenic cause of primary hypertrophic osteoarthropathy $(8,9)$. SLCO2A1 mutations have been documented in Korean and Chinese families (10). There are other reports related to chromosomal abnormalities and HLA-B12 antigen associations (11). Although it is known that one third of PDP patients have a family history, our patient had no family members diagnosed with PDP.

Pachydermoperiostosis is very rare, and its clinical and radiological presentations can be confused with those of acromegaly, pseudoacromegaly with severe insulin resistance, Marfan's syndrome, McCune Albright syndrome, syphilitic periostitis, psoriatic onychopachydermo-periostitis (POPP) and Paget's disease. In this case, the serum IGF1 was at the lower end of normal, which is against the diagnosis of acromegaly. This is similar to the condition in a patient reported recently by Karimova et al. (2). However, currently, there is no reasonable explanation for this interesting finding. The clubbing of digits, coarse facial features and enlarged hands and feet from periosteal thickening in patients with PDP can be misleading as soft tissue thickening 
and enlargement of the distal phalanx of the digits along with hypertrophy of the bones and soft tissue are described in patients with acromegaly. Other similarities include hyperhidrosis, excess sebum production and joint pain. These features that are present in patients with acromegaly are due to the effect of excess growth hormones, mainly from pituitary tumours. The articular manifestations of acromegaly, a major cause of morbidity and functional disability, are similar to those of osteoarthritis, particularly in the appendicular and axial skeleton. Inflammation is not prominent, and synovial effusion is uncommon. The weight bearing joints, such as the knees and ankles, are most commonly affected in HPOA, and joint swelling is frequently seen in conjunction with the synovial fluid in the rare cases where inflammation occurs (12).

The clues for the differentiation of HPOA are digital clubbing and periostosis, which are not features of acromegaly. Abnormal hormonal profiles should be excluded for a proper diagnosis. A definitive treatment for PDP has not been established, but symptomatic management with non-steroidal anti-inflammatory drugs (NSAIDs), simple analgesics and intravenous bisphosphonates is currently being used (13). In addition, tamoxifen has been reported to be effective for arthralgia that is refractory to NSAIDs (14).

In conclusion, clinical presentations of pachydermoperiostosis can be confused with multiple other diagnoses, especially acromegaly. This great mimicker should be considered in the differential diagnosis of individuals presenting with acromegaloid features.

\section{Patient's perspective}

For 2 years, I was told that I had acromegaly and I was even asked to participate in MRCP PACES examination as an acromegalic patient. I went through a battery of tests including repeated MRI but the doctors could not find any tumour. So, when I went to a different hospital and was told it was not acromegaly, it came as a shock at the beginning. I have been doing a lot of reading about acromegaly and the treatments available to cure the disease. The knee and the ankle pain were unbearable at times. I cannot do sports that I enjoy or even walk. Now the doctors are telling me it is a different disease which has no cure for it. I was devastated, as all I want is cure and to lead a normal life again.

\section{Declaration of interest}

The authors declare that there is no conflict of interest that could be perceived as prejudicing the impartiality of the research reported.
Funding

This research did not receive any specific grant from any funding agency in the public, commercial or not-for-profit sector.

\section{Patient consent}

Written informed consent has been obtained from the patient and the patient's guardian for publication of the submitted article and accompanying images.

\section{Author contribution statement}

All authors are from the endocrinology team who were directly involved in the care of this patient prepared the manuscript for submission. Special acknowledgements to Dr Nor Shuhaila Shahril, a Consultant Physician and Rheumatologist, Dr Malehah Mohd Noh, a clinical fellow in rheumatology and Dr Nazatul, a Consultant Dermatologist who have played instrumental role in the care of this patient and facilitated the diagnostic workup. Special acknowledgment to Dr Navarasi S Raja Gopal, a pathologist who prepared, analysed the histological specimen and contributed the imaging for the publication.

\section{References}

1 Kwon M-H \& Joung C-I 2012 Pachydermoperiostosis Mimicking Acromegaly: a case report. Archives of Rheumatology 27 132-135. (doi:10.5606/tjr.2012.020)

2 Karimova MM, Halimova ZY, Urmanova YM, Korbonits M, Cranston T \& Grossman AB 2017 Pachydermoperiostosis Masquerading as Acromegaly. Journal of the Endocrine Society 1 109-112.

3 Friedrich N 1868 Hyperostose des gesammten skelettes. Virchows Archiv. A, Pathological Anatomy and Histopathology 43 83-87. (doi:10.1007/BF02117271)

4 Benedek TG 1993 Paraneoplastic digital clubbing and hypertrophic osteoarthropathy. Clinics in Dermatology 11 53-59. (doi:10.1016/0738081X(93)90082-N)

5 Atkinson S \& Fox SB 2004 Vascular endothelial growth factor (VEGF)-A and platelet-derived growth factor (PDGF) play a central role in the pathogenesis of digital clubbing. Journal of Pathology $\mathbf{2 0 3}$ 721-728. (doi:10.1002/path.1565)

6 Uppal S, Diggle CP, Carr IM, Fishwick CW, Ahmed M, Ibrahim GH, Helliwell PS, Latos-Bieleńska A, Phillips EV, Markham AF et al. 2008 Mutations in 15-hydroxyprostaglandin dehydrogenase cause primary hypertrophic osteoarthropathy. Nature Genetics 40 789-793. (doi:10.1038/ng.153)

7 Yüksel-Konuk B, Sırmacı A, Ayten GE, Özdemir M, Aslan İ, YılmazTuray Ü, Erdoğan Y, \& Tekin M 2009 Homozygous mutations in the 15-hydroxyprostaglandin dehydrogenase gene in patients with primary hypertrophic osteoarthropathy. Rheumatology International 30 39-43. (doi:10.1007/s00296-009-0895-6)

8 Zhang Z, Xia W, He J, Zhang Z, Ke Y, Yue H, Wang C, Zhang H, Gu J, $\mathrm{Hu} \mathrm{W}$ et al. 2012 Exome Sequencing Identifies SLCO2A1 Mutations as a Cause of Primary Hypertrophic Osteoarthropathy. American Journal of Human Genetics 90 125-132. (doi:10.1016/j.ajhg.2011.11.019)

9 Diggle CP, Parry DA, Logan CV, Laissue P, Rivera C, Restrepo CM, Fonseca DJ, Morgan JE, Allanore Y, Fontenay M, et al. 2012 Prostaglandin transporter mutations cause pachydermoperiostosis with myelofibrosis. Human Mutation 33 1175-1181. (doi:10.1002/ humu.22111) 
10 Lee S, Park SY, Kwon HJ, Lee C-H, Kim O-H \& Rhee Y 2016 Identification of the Mutations in the Prostaglandin Transporter Gene, SLCO2A1 and Clinical Characterization in Korean Patients with Pachydermoperiostosis. Journal of Korean Medical Science 31 735-742. (doi:10.3346/jkms.2016.31.5.735)

11 Jajic I, Ozie-Bebek M 1992 HLA antigens and primary hypertrophic osteoarthropathy. Clinical and Experimental Rheumatology 1074.

12 Pineda C, Fonseca C \& Martinez-Lavin M 1990 The spectrum of soft tissue and skeletal abnormalities of hypertrophic osteoarthropathy. Journal of Rheumatology 17 626-632.
13 Guyot-Drouot M-H, Solau-Gervais E, Cortet B, Deprez X, Chastanet P, Cotten A, Delcambre B \& Flipo RM 2000 Rheumatologic manifestations of pachydermoperiostosis and preliminary experience with bisphosphonates. Journal of Rheumatology 27 2418-2423.

14 Maeda H, Kumagai K, Konishi F, Katayama Y, Hiyama K, Ishioka S \& Yamakido M 2000 Successful treatment of arthralgia with tamoxifen citrate in a patient with pachydermoperiostosis. Rheumatology 39 1158-1159. (doi:10.1093/rheumatology/39.10.1158)

Received in final form 3 April 2017

Accepted 11 April 2017 